\title{
Interpolation-Collocation Method of Solution for Solving Poisson Equation
}

\section{Sunday Babuba*}

Department of Mathematics, Federal University Dutse, Nigeria

\begin{abstract}
In this paper, we consider the system of algebraic equations arising from the discretization of elliptic partial differential equation with respect to $x$ and $y$ axes. To compute the solution of the resulting equations we use the new method to solve various elliptic equations. We study the numerical accuracy of the method. The numerical results have shown that the method provided exact result depending on the particular equation on which the scheme is applied.
\end{abstract}

Keywords: Continuous method; Lines; Multistep collocation; Elliptic; Taylor's polynomial

\section{Introduction}

A finite difference scheme with continuous coefficients for the approximate solution of elliptic partial differential equation of the form

$$
\nabla^{2} U(x, y)=\frac{\partial^{2} U}{\partial x^{2}}(x, y)+\frac{\partial^{2} U(x, y)}{\partial y^{2}}=f(x, y) \quad \text { for }(x, y) \in R
$$

And $U(x, y)=G(x, y)$ for $(x, y) \in S$ where $\mathrm{R}=\{(x, y): a<x<b, c<y<d$ and $S$ enotes the boundary of $R$ is proposed. For this discussion we assume that both $f$ and $g$ are continuous on their domains so that a unique solution to equation (1.0) is ensured. The method to be used is the adaptation of the canonical polynomials $Q_{r}(x, y)$ [1-17]. Many problems in engineering and sciences cannot be formulated in terms of partial differential equations. The vast majority of equations encountered in practice cannot, however, be solved analytically, and recourse must necessarily be made to numerical methods.

\section{Our Present Method}

The basic method seeks an approximation of the form:

$$
U(x, y)=\sum_{r=0}^{p-2} a_{r} Q_{r}(x, y), \quad x \in\left[x_{m}, x_{m+l}\right] \quad r=0,1 \ldots, p-2
$$

Such that $0=x_{0}<\ldots<x_{i} \ldots<x_{N}=X$ The basis function, $Q_{r}(x, y)=x^{r} y^{r}, r=0,1, \ldots, p-2$ are assumed known, $a_{r}$ are constants to be determined and $p \leq l+s$, where $s$ is the number of collocation points. The equality holds if the number of interpolation points used is equal to $l$. There will be flexibility in the choice of the basis function $Q_{r}(x, y)$ as may be desired for specific application. For this work, we consider the Taylor's polynomial $Q_{r}(x, y)=x^{r} y^{r}$. The interpolation values $\mathrm{U}_{m, n}, \ldots, U_{m+1-1}{ }^{\prime}$ are assumed to have been determined from previous steps, while the method seeks to obtain $U_{m+1-r_{n} n}$ [8-27].

We apply the above interpolation conditions on eqn. (2.0) to obtain:

$a_{0} Q_{0}\left(x_{m+g}, y_{n}\right)+\ldots+a_{p-2} Q_{p-2}\left(x_{m+g}, y_{n}\right)=U\left(x_{m+g}, y_{n}\right) \quad g=-1(1) l-2(2.1)$

We can write eqn. (2.1) as a simple matrix equation as,

$$
\left[\begin{array}{cll}
Q_{0}\left(x_{m-1}, y_{n}\right) & \ldots & Q_{p-2}\left(x_{m-1}, y_{n}\right) \\
Q_{0}\left(x_{m}, y_{n}\right) & \ldots & Q_{p 2}\left(x_{m}, y_{n}\right) \\
\ldots & \ldots & \ldots \\
\ldots & \ldots & \ldots \\
\ldots & \ldots & \ldots \\
Q_{0}\left(x_{m+l-2}, y_{n}\right) & \ldots & Q_{p-2}\left(x_{m+l-2}, y_{n}\right)
\end{array}\right]\left[\begin{array}{l} 
\\
\ldots \\
\ldots \\
\ldots \\
\ldots \\
\ldots \\
U \\
U \\
\end{array}\right]
$$

Using three interpolation points and one collocation point, eqn (2.1) becomes,

$$
a_{0} Q_{0}\left(x_{m+g}, y_{n}\right)+a_{1} Q_{1}\left(x_{m+g}, y_{n}\right)+a_{2} Q_{2}\left(x_{m+g}, y_{n}\right)=U_{m+g},_{n}
$$

Putting the values of $g$ in eqn. (2.3) and writing it as a matrix we obtain,

$$
\left[\begin{array}{lll}
Q_{0}\left(x_{m-1}, y_{n}\right) & Q_{1}\left(x_{m-1}, y_{n}\right) & Q_{2}\left(x_{m-1}, y_{n}\right) \\
Q_{0}\left(x_{m}, y_{n}\right) & Q_{1}\left(x_{m}, y_{n}\right) & Q_{2}\left(x_{m}, y_{n}\right) \\
Q_{0}\left(x_{m+1}, y_{n}\right) & Q_{1}\left(x_{m+1}, y_{n}\right) & Q_{2}\left(x_{m+1}, y_{n}\right)
\end{array}\right]\left[\begin{array}{l}
a_{0} \\
a_{1} \\
a_{3}
\end{array}\right]=\left[\begin{array}{l}
U_{m-1, n} \\
U_{m . n} \\
U_{m+1, n}
\end{array}\right]
$$

From eqn. (2.4) we obtain

$$
\left[\begin{array}{ccc}
1 & x_{m-1} y_{n} & x^{2}{ }_{m-1} y^{2} \\
1 & x_{m} y_{n} & x^{2}{ }_{m} y_{n}^{2} \\
1 & x_{m+1} y_{n} & x_{m+1}^{2} y_{n}{ }_{n}
\end{array}\right]\left[\begin{array}{l}
a_{0} \\
a_{1} \\
a_{2}
\end{array}\right]=\left[\begin{array}{l}
U_{m-1, n} \\
U_{m \cdot n} \\
U_{m+1, n}
\end{array}\right]
$$

We solve eqn. (2.5) to obtain the value of $a_{2}$ as:

$$
a_{2}=\frac{U_{m+1, n}+U_{m-1, n}-2 U_{m, n}}{2 h^{2} y_{n}^{2}},
$$

Using 3 interpolation points and 1 collocation point, implies that $r$. Putting the values of $r$ in eqn. (2.0) we obtain

$$
U(x, y)=a_{0} Q_{0}+a_{1} Q_{1}+a_{2} Q_{2}
$$

By substitution of $Q_{0}, Q_{1}$ and $Q_{2}$ in eqn. (2.6) we obtain

$$
U(x, y)=a_{0}+a_{1} x y+a_{2} x^{2} y^{2}
$$

Substituting the value of $a_{2}$ in eqn. (2.7) we have

$$
U(x, y)=a_{0}+a_{1} x y+x^{2} y^{2}\left(\frac{U_{m+1, n}+U_{m-1, n}-2 U_{m, n}}{2 h^{2} y^{2}{ }_{n}}\right)
$$

${ }^{*}$ Corresponding author: Sunday Babuba, Department of Mathematics, Federa University Dutse, Nigeria, Tel: 0807079 3965; E-mail: sundaydzupu@yahoo.com Received October 12, 2017; Accepted January 21, 2018; Published January 30 2018

Citation: Babuba S (2018) Interpolation-Collocation Method of Solution for Solving Poisson Equation. J Biom Biostat 9: 388. doi: 10.4172/2155-6180.1000388

Copyright: @ 2018 Babuba S. This is an open-access article distributed under the terms of the Creative Commons Attribution License, which permits unrestricted use, distribution, and reproduction in any medium, provided the original author and source are credited. 
Citation: Babuba S (2018) Interpolation-Collocation Method of Solution for Solving Poisson Equation. J Biom Biostat 9: 388. doi: 10.4172/21556180.1000388

Page 2 of 3

Taken the first and second derivatives of eqn. (2.8) with respect to $x$ we have

$$
U^{\prime \prime}(x, t)=y^{2}\left(\frac{U_{m+1, n}+U_{m-1, n}-2 U_{m, n}}{h^{2} y^{2}{ }_{n}}\right)
$$

We collocate eqn. (2.9) at $y=y_{n}$, we obtain:

$$
U^{\prime \prime}(x, y)=\frac{U_{m+1, n}+U_{m-1, n}-2 U_{m, n}}{h^{2}}
$$

We interchange the roles of $x$ and $y$ in eqn. (2.0) and applying the same interpolation conditions we obtain,

$$
a_{0} Q_{0}\left(x_{m}, y_{n+g}\right)+\ldots+a_{p-2} Q_{p-2}\left(x_{m}, y_{n+g}\right)=U\left(x_{m}, y_{n+g}\right)
$$

We can write eqn. (2.11) as a simple matrix equation as,

$$
\left[\begin{array}{ccl}
Q_{0}\left(x_{m}, y_{n-1}\right) & \ldots & Q_{p-2}\left(x_{m}, y_{n-1}\right) \\
\ldots & \ldots & \ldots \\
\ldots & \ldots & \ldots \\
\ldots & \ldots & \ldots \\
Q_{0}\left(x_{m}, y_{n+l-2}\right) & \ldots & Q_{p-2}\left(x_{m}, y_{n+l-2}\right)
\end{array}\right]\left[\begin{array}{l}
a_{0} \\
\ldots \\
\ldots \\
\ldots \\
a_{p-2}
\end{array}\right]=\left[\begin{array}{l}
U\left(x_{m}, y_{n-1}\right) \\
\ldots \\
\ldots \\
\ldots \\
U\left(x_{m}, y_{n+l-2}\right)
\end{array}\right]
$$

Using 3 interpolation and 1 collocation points, eqn. (2.11) becomes,

$$
a_{0} Q_{0}\left(x_{m}, y_{n+g}\right)+a_{1} Q_{1}\left(x_{m}, y_{n+g}\right)+a_{2} Q_{2}\left(x_{m}, y_{n+g}\right)=U_{m}, n+g \quad g=-1,0,1
$$

Putting the values of $g$ in eqn. (2.13) and writing it as a matrix we obtain,

$$
\left[\begin{array}{lll}
Q_{0}\left(x_{m}, y_{n-1}\right) & Q_{1}\left(x_{m}, y_{n-1}\right) & Q_{2}\left(x_{m}, y_{n-1}\right) \\
Q_{0}\left(x_{m}, y_{n}\right) & Q_{1}\left(x_{m}, y_{n}\right) & Q_{2}\left(x_{m}, y_{n}\right) \\
Q_{0}\left(x_{m}, y_{n+1}\right) & Q_{1}\left(x_{m}, y_{n+1}\right) & Q_{2}\left(x_{m}, y_{n+1}\right)
\end{array}\right]\left[\begin{array}{l}
a_{0} \\
a_{1} \\
a_{3}
\end{array}\right]=\left[\begin{array}{l}
U_{m, n-1} \\
U_{m \cdot n} \\
U_{m, n+1}
\end{array}\right]
$$

From eqn. (2.14) we obtain

$$
\left[\begin{array}{ccc}
1 & x_{m} y_{n-1} & x^{2}{ }_{m} y^{2}{ }_{n-1} \\
1 & x_{m} y_{n} & x_{m}^{2} y^{2}{ }_{n} \\
1 & x_{m} y_{n+1} & x^{2}{ }_{m} y^{2}{ }_{n+1}
\end{array}\right]\left[\begin{array}{l}
a_{0} \\
a_{1} \\
a_{2}
\end{array}\right]=\left[\begin{array}{l}
U_{m, n-1} \\
U_{m, n} \\
U_{m, n+1}
\end{array}\right]
$$

We solve eqn. (2.15) to obtain the value of $a_{2}$ as,

$$
a_{2}=\frac{U_{m, n+1}+U_{m, n-1}-2 U_{m, n}}{2 h^{2} y_{n}^{2}}
$$

Using 3 interpolation points and 1 collocation point implies that $r$. Putting the values of $r$ in eqn. (2.0) we obtain,

$$
U(x, y)=a_{0} Q_{0}+a_{1} Q_{1}+a_{2} Q_{2}
$$

By substitution of $Q_{0}, Q_{1}$ and $Q_{2}$ in eqn. (2.16) we obtain

$$
U(x, y)=a_{0}+a_{1} x y+a_{2} x^{2} y^{2}
$$

Substituting the value of $a_{2}$ in eqn. (2.17) we have

$$
U(x, y)=a_{0}+a_{1} x y+x^{2} y^{2}\left(\frac{U_{m, n+1}+U_{m, n-1}-2 U_{m, n}}{2 h^{2} y_{n}^{2}}\right)
$$

Taken the first and second derivatives of eqn. (2.18) with respect to $y$ we have

$$
U^{\prime \prime}(x, y)=x^{2}\left(\frac{U_{m, n+1}+U_{m, n-1}-2 U_{m, n}}{h^{2} x^{2}{ }_{n}}\right)
$$

We collocate eqn. (2.19) at $x=x_{n}$ to arrive at

$$
U^{\prime \prime}(x, y)=\frac{U_{m, n+1}+U_{m, n-1}-2 U_{m, n}}{h^{2}}
$$

Substituting eqns. (2.10) and (2.20) in eqn. (1.0) we obtain a scheme that solves elliptic equation. To illustrate the method we use it to solve two test problems (3.1) and (3.2) respectively.

\section{Specific Problem}

\section{Example 3.1}

Use the scheme to approximate the solution of a problem of determining the steady-state heat in a thin metal plate in the shape of a square with dimensions 0.5 meters by 0.5 meters, which is held at $0^{\circ}$ Celsius on two adjacent boundaries while the heat on the other boundaries increase linearly from $0^{\circ}$ Celsius at one corner to $100^{\circ}$ Celsius where these sides meet. If we replace the sides with zero boundary conditions along the $\mathrm{x}$ - and $\mathrm{y}$-axes, the problem is expressed mathematically as:

$$
\frac{\partial^{2} U}{\partial x^{2}}-\frac{\partial^{2} U}{\partial y^{2}}=0
$$

for $(x, y)$ in the $=\{(x, y): 0<x<.5,0<y<.5$ with the boundary conditions $U(0, y)=U(x, 0)=0$ and $U(x, .5)=200 x, U(.5, y)=200 y$

The exact solution of the problem is $U(x, . y)=400 x y$

Using mesh size of 0.125 on each axis, the method gives us the result as shown in Table 1 .

\section{Example 3.2}

Use the scheme to approximate the solution to the Poisson's equation

$$
\frac{\partial^{2} U}{\partial x^{2}}+\frac{\partial^{2} U}{y x^{2}}=x e^{y} \quad 0<x<2, \quad 0<y<1
$$

With the boundary conditions

$$
\begin{array}{ll}
U(0, y)=0, \quad U(2, y)=2 e^{y}, & 0 \leq y \leq 1 \\
U(x, 0)=x, \quad U(x, 1)=e x, & 0 \leq x \leq 2
\end{array}
$$

The exact solution of the problem is $U(x, y)=x e^{y}$. Using a mesh size of 0.3333 on the axis $x$ and 0.2000 on the $y$-axis we obtain the following result (Table 2).

\section{Conclusion}

A continuous interpolation collocation method is proposed for solving elliptic partial differential equations. To check the numerical method, it is applied to solve two (2) different test problems with known

\begin{tabular}{|c|c|c|c|c|c|}
\hline $\boldsymbol{i}$ & $\boldsymbol{j}$ & $\boldsymbol{x}_{\boldsymbol{i}}$ & $\boldsymbol{Y}_{\boldsymbol{j}}$ & Our Method & Exact result \\
\hline 1 & 3 & 0.125 & 0.375 & 18.75 & 18.75 \\
\hline 2 & 3 & 0.250 & 0.375 & 37.50 & 37.50 \\
\hline 3 & 3 & 0.375 & 0.375 & 56.25 & 56.25 \\
\hline 1 & 2 & 0.125 & 0.250 & 12.50 & 12.50 \\
\hline 2 & 2 & 0.250 & 0.250 & 25.00 & 25.00 \\
\hline 3 & 2 & 0.375 & 0.250 & 37.50 & 37.50 \\
\hline 1 & 1 & 0.125 & 0.125 & 6.25 & 6.25 \\
\hline 2 & 1 & 0.250 & 0.125 & 12.50 & 12.50 \\
\hline 3 & 1 & 0.375 & 0.125 & 18.75 & 18.75 \\
\hline
\end{tabular}

Table 1: Result of action of eqn. (2.21) on problem 3.1. 
Citation: Babuba S (2018) Interpolation-Collocation Method of Solution for Solving Poisson Equation. J Biom Biostat 9: 388. doi: 10.4172/21556180.1000388

Page 3 of 3

\begin{tabular}{|c|c|c|c|c|c|c|}
\hline $\boldsymbol{i}$ & $\boldsymbol{j}$ & $\boldsymbol{x}_{\boldsymbol{i}}$ & $\boldsymbol{y}_{\boldsymbol{j}}$ & Our method & Exact result & Error \\
\hline 1 & 1 & 0.3333 & 0.2000 & 0.40726 & 0.40713 & $1.30 \times 10^{-4}$ \\
\hline 1 & 2 & 0.3333 & 0.4000 & 0.49748 & 0.49727 & $2.08 \times 10^{-4}$ \\
\hline 1 & 3 & 0.3333 & 0.6000 & 0.60760 & 0.60737 & $2.23 \times 10^{-4}$ \\
\hline 1 & 4 & 0.3333 & 0.8000 & 0.74201 & 0.74185 & $1.60 \times 10^{-4}$ \\
\hline 2 & 1 & 0.6667 & 0.2000 & 0.81452 & 0.81472 & $2.55 \times 10^{-4}$ \\
\hline 2 & 2 & 0.6667 & 0.4000 & 0.99496 & 0.99455 & $4.08 \times 10^{-4}$ \\
\hline 2 & 3 & 0.6667 & 0.6000 & 1.21520 & 1.21470 & $4.37 \times 10^{-4}$ \\
\hline 2 & 4 & 0.6667 & 0.8000 & 1.48400 & 1.48370 & $3.15 \times 10^{-4}$ \\
\hline 3 & 1 & 1.0000 & 0.2000 & 1.22180 & 1.22140 & $3.64 \times 10^{-4}$ \\
\hline 3 & 2 & 1.0000 & 0.4000 & 1.49240 & 1.49180 & $5.80 \times 10^{-4}$ \\
\hline 3 & 3 & 1.0000 & 0.6000 & 1.82270 & 1.82210 & $6.24 \times 10^{-4}$ \\
\hline 3 & 4 & 1.0000 & 0.8000 & 2.22600 & 2.22550 & $4.51 \times 10^{-4}$ \\
\hline 4 & 1 & 1.3333 & 0.2000 & 1.62900 & 1.62850 & $4.27 \times 10^{-4}$ \\
\hline 4 & 2 & 1.3333 & 0.4000 & 1.98980 & 1.98910 & $6.79 \times 10^{-4}$ \\
\hline 4 & 3 & 1.3333 & 0.6000 & 2.43020 & 2.42950 & $7.35 \times 10^{-4}$ \\
\hline 4 & 4 & 1.3333 & 0.8000 & 2.96790 & 2.96740 & $5.40 \times 10^{-4}$ \\
\hline 5 & 1 & 1.6670 & 0.2000 & 2.03600 & 2.03570 & $3.71 \times 10^{-4}$ \\
\hline 5 & 2 & 1.6670 & 0.4000 & 2.48700 & 2.48640 & $5.84 \times 10^{-4}$ \\
\hline 5 & 3 & 1.6670 & 0.6000 & 3.03750 & 3.03690 & $6.41 \times 10^{-4}$ \\
\hline 5 & 4 & 1.6670 & 0.8000 & 3.70970 & 3.70920 & $4.89 \times 10^{-4}$ \\
\hline & & & 2.8690 & & \\
\hline
\end{tabular}

Table 2: Result of action of eqn. (2.21) on problem 3.2.

exact solutions. The scheme produced real values in test problem 1 , while there is small deviation from the exact solutions in the result of the second test problem. The numerical results confirm the validity of the new numerical scheme and suggest that it is a viable numerical method which involves the reduction of PDE to a system of ODEs.

\section{References}

1. Adam A, David R (2002) One dimensional heat equation.

2. Awoyemi DO (2002) An Algorithmic collocation approach for direct solution of special fourth - order initial value problems of ordinary differential equations. Journal of the Nigerian Association of Mathematical Physics 6: 271-284.

3. Awoyemi DO (2003) A p-stable linear multistep method for solving general third order. Ordinary differential equations. Int J Computer Math 80: 987-993.

4. Bao W, Jaksch P, Markowich PA (2003) Numerical solution of the GrossPitaevskii equation for Bose-Einstein condensation. J Compt Phys 187: 318-342.

5. Benner P, Mena H (2004) BDF methods for large scale differential Riccati equations in proc of mathematical theory of network and systems.

6. Bensoussan A, Da Prato G, Delfour MC, Mitter S (2007) Representation and control of infinite dimensional systems. (2ndedn), Birkhauser, Boston.

7. Motmans B, Willems J, Dooren PV, Blondel V, Biazar J, et al. (2005) An approximation to the solution of hyperbolic equation by a domain decomposition method and comparison with characteristics method. Appl Math and Comput 163: 633-648.

8. Brown PLT (1979) A transient heat conduction problem. AICHE Journal 16 207-215.

9. Chawla MM, Katti CP (1979) Finite difference methods for two-point boundary value problems involving high-order differential equations. BIT 19: 27-39.

10. Cook RD (1974) Concepts and Application of Finite Element Analysis. Wiley Eastern Limited, NY, USA.

11. Crandall SH (1955) An optimum implicit recurrence formula for the heat conduction equation. JACM. 13: 318-327.

12. Crane RL, Klopfenstein RW (1965) A predictor-corrector algorithm with increased range of absolute stability. JACM 12: 227-237.

13. Crank J, Nicolson P (1947) A practical method for numerical evaluation of solutions of partial differential equations of heat conduction type. Proc Camb Phil Soc 6: 32-50.

14. Dahlquist G, Bjorck A (1974) Numerical methods. Prentice, NY, USA.

15. Dehghan $M(2003)$ Numerical solution of a parabolic equation with non-local boundary specification. Appl Math Comput 145: 185-194.

16. Dieci L (1992) Numerical analysis. SIAM Journal 29: 781-815.

17. Douglas J (1961) A Survey of Numerical Methods for Parabolic Differential Equations in advances in computer II. Academic press.

18. Yakonov EG (1963) On the application of disintegrating difference operators. Z Vycist Mat I Mat Fiz 3: 385-395.

19. Eyaya BE (2010) Computation of the matrix exponential with application to linear parabolic PDEs.

20. Fox $L$ (1962) Numerical Solution of Ordinary and Partial Differential Equation. Pergamon, New York.

21. Penzl T (2000) Matrix analysis. SIAM J 21: 1401-1418.

22. Pierre J (2008) Numerical solution of the dirichlet problem for elliptic parabolic equations. SIAM J Soc Indust Appl Math 6: 458-466.

23. Richard LB, Albert C (1981) Numerical analysis. Prindle Weber and Schmidt, Berlin.

24. Richard L, Burden J, Douglas F (2001) Numerical analysis. Thomson Learning Academic Resource Center.

25. Saumaya B, Neela N, Amiya YY (2012) Semi discrete Galerkin method fo equations of Motion arising in Kelvin-Voitght model of viscoelastic fluid flow. Journal of Pure and Applied Science 3: 321-343.

26. Yildiz B, Subasi M (2001) On the optimal control problem for linear Schrodinger equation. Appl Math and Comput 121: 373-381.

27. Yin Z, Rui $H, X u Q$ (2012) An approximation of incompressible miscible displacement in porous media by mixed finite elements and symmetric finite volume element method of characteristics. Applied Mathematics and Computation. Elsevier 143: 654-672. 